\title{
Redox Processes of Ruthenium(II) Polypyridine Complexes Induced by Fast-Atom Bombardment Mass Spectrometry
}

\author{
Gianfranco Denti and Scolastica Serroni \\ Laboratorio di Chinica Inorganica, Istituto di Chimica Agraria, Università di Pisa, Pisa, Italy
}

Giovanni Sindona and Nicola Uccella

Dipartimento di Chimica, Università della Calabria, Calabria, Italy

\begin{abstract}
Fast-atom bombardment (FAB) mass spectrometry in the negative ionization mode enables the sputtering into the gas phase of the ruthenium complexes $\left[R u\left(2,2^{\prime} \text {-bipyridine }[\mathrm{bpy}]\right)_{2}(2,5-\right.$ bis(pyrydil)pyrazine[dpp])](PF $)_{2} ; \quad\left[\mathrm{Ru}(\mathrm{bpy})_{2}(2,3-\mathrm{dpp})\right]\left(\mathrm{PF}_{6}\right)_{2} ; \quad\left[\mathrm{Ru}(\mathrm{bpy})_{2}(2,3-\mathrm{dpp}-\mathrm{Me})\right]\left(\mathrm{PF}_{6}\right)_{3} ;$ and $\left[\mathrm{Ru}(\mathrm{bpy})_{2}(\mu-2,3-\mathrm{dpp})\right]_{2} \mathrm{RuCl}_{2}\left(\mathrm{PF}_{6}\right)_{4}$ as intact radical anions. These data, combined with those available from the positive $\mathrm{FAB}$ spectra, allow a full characterization of the analytes. (j Am Soc Mass Spectrom 1993, 4, 306-311)
\end{abstract}

$\mathrm{P}$ olynuclear luminescent and redox-reactive rutheniumII $[R u(I I)]$ polypyridine complexes are attracting increasing interest because of their relevance for the design of photochemical molecular devices [1]. Ruthenium(II) complexes have also found exciting applications in the biomolecular sciences as shape-selective probes of nucleic acid structure [2]. An important family of such compounds is that based on the 2,3- and 2,5-isomers of bis(pyrydil)pyrazine (dpp) as bridging ligands and on 2,2'-bipyridine (bpy) as the terminal ligand [3]. Their chemical characterization is complicated because they can be mixtures of several diastereomeric species, owing to the chiral nature of each metal center. This fact strongly limits the use of nuclear magnetic resonance and prevents that of $\mathrm{X}$-ray diffractometry for determining the chemical composition and structural features of intermediate and final products. In this context, mass spectrometry represents an appropriate tool for the characterization of new species and can offer the possibility of gaining insight into their interesting gas-phase ion chemistry.

Fast-atom bombardment (FAB) mass spectrometry has been used in the structural determination of Ru(II) complexes [4, 5]. Substrates of the general formula $\left[\mathrm{RuL}_{2} \mathrm{~L}^{\prime}\right] \mathrm{X}_{2}$ exposed to atom bombardment in 3-nitrobenzyl alcohol (NBA) matrix afford, in the

Address reprint requests to Giovanni Sindona, Dipartimento di Chimica, Università della Calabria, 87030 Arcavacata di Rende (CS), Italy. positive ionization mode, $[5,6]$, ions corresponding to $\left[\mathrm{RuL}_{2} \mathrm{~L}^{\prime} \mathrm{X}\right]^{+}(\mathrm{I})$ and $\left[\mathrm{RuL}_{2} \mathrm{~L}^{\prime}\right]^{2+}(\mathrm{II})$, together with some other diagnostic fragments. No information on the composition of the intact molecule can be obtained, whereas the structure of the cationic moiety can be inferred from the presence in the spectrum of doubly charged species of structure type (II) [6] and from the low-energy collision-induced dissociation (CID) of cations of type (I) [5].

One possible mechanism of ion formation by kiloelectron volt particle bombardment is the production of low-energy electrons $(0-3 \mathrm{eV})$ that can be captured by low-lying lowest unoccupied molecular orbitals (LUMOs) of the analytes. This process can give rise to intact radical anions [7] and to reduced multiprotonated cations [8]. The occurrence of redox reactions indured by FAB has been widely dorimented [9-14]. The typical first and second reduction potentials of dpp and byp Ru(II) complexes versus standard calomel electrode are in the ranges $[3,15]-0.5$ to -1.1 and -0.6 to $-1.5 \mathrm{~V}$, respectively. It should be possible therefore to induce by particle bombardment the reduction of this species and the release of intact radical anions.

\section{Experimental}

Compounds 1-4 has been synthesized as previously described [3]. The spectra were obtained on a Fisons- 
VG ZAB $2 F$ instrument operated at an acceleration potential of $8 \mathrm{keV}$ by using the M-SCAN steerable FAB gun. A neutral Xe beam of $9.5-\mathrm{keV}$ energy and a neutral current of approximately $10 \mu \mathrm{A}$ were used. The samples were prepared by directly mixing the analyte with NBA matrix. The resolution of the instrument was set to values suitable for collecting spectra of primary ions with unit resolution. Collision-induced dissociation spectra were obtained in the second fieldfree region of the instrument by allowing the species of $8-\mathrm{keV}$ translational energy, transmitted by the magnet, to collide with helium. The collision gas pressure was adjusted to values that attenuated the main beam of ions by $50 \%$.

\section{Results and Discussion}

The ruthenium complexes $\left[R u(b p y)_{2}(2,5-d p p)\right]\left(P_{6}\right)_{2}$ (1); $\left[R u(b p y)_{2}(2,3-d p p)\right]\left(P_{6}\right)_{2}$ (2); [Ru(bpy $)_{2}(2,3-d p p-$ $\left.\mathrm{Me}) \mathrm{PPF}_{\mathrm{h}}\right)_{3}(3)$; and $\left[\mathrm{Ru}(\mathrm{bpy})_{2}(\mu-2,3-\mathrm{dpp})\right]_{2} \mathrm{RuCl}_{2}\left(\mathrm{PF}_{6}\right)_{4}$ (4), synthesized as previously described [3], were analyzed by FAB mass spectrometry in the positive $(+)$ and negative $(-)$ ionization modes by means of a $B-E$ sector-type instrument using NBA as matrix. The ion cluster of highest mass observable in the $(+)$ spectra of 1-4 was due as expected $[5,6]$ to the release of a single $\mathrm{PF}_{6}^{-}$counterion from the intact molecules, affording the species $\left({ }^{102} \mathrm{Ru},{ }^{35} \mathrm{Cl}\right)$ at $m / z 793,953$, and 1903 for 1 (or 2), 3, and 4, respectively.

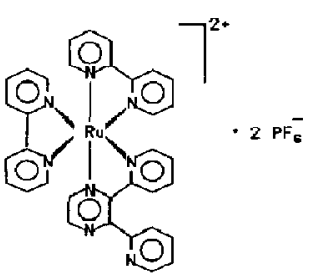

(1)

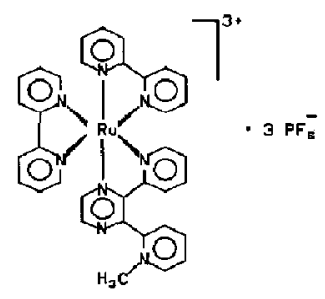

(3)

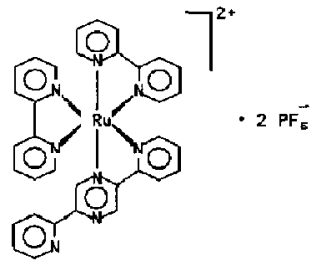

(2)

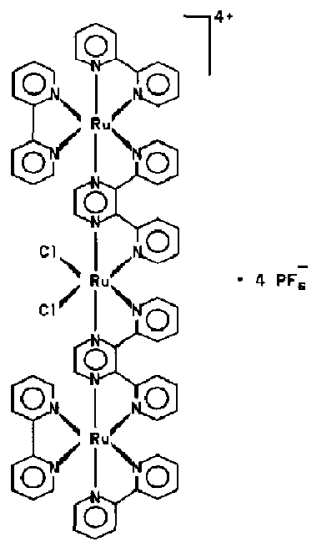

(4)
The isomeric complexes 1 and 2 gave almost superimposable spectra characterized by the presence of fragments at $m / z 663,648,647,492,491,414,413$, and 324 of composition [Ru(bpy) ${ }_{2}(2,5-\mathrm{dpp})-\mathrm{H}+\mathrm{O}^{+}$; $\left[\mathrm{Ru}(\mathrm{bpy})_{2}(2,5-\mathrm{dpp}]^{+} ; \quad\left[\mathrm{Ru}(\mathrm{bpy})_{2}(2,5-\mathrm{d} p \mathrm{p})-\mathrm{H}\right]^{+}\right.$; $\left[\mathrm{Ru}(\mathrm{bpy})(2,5 \text {-dpp) }]^{+} ; \quad[\mathrm{Ru}(\mathrm{bpy})(2,5-\mathrm{d} p \mathrm{p})-\mathrm{H}]^{+}\right.$; $\left[\mathrm{Ru}(\mathrm{bpy})_{2}\right]^{+} ; \quad\left[\mathrm{Ru}(\mathrm{bpy})_{2}-\mathrm{H}\right]^{+}$; and $\left[\mathrm{Ru}(\mathrm{bpy})_{2}(2,5-\right.$ $\mathrm{dpp})]^{2+}$, respectively. The proton abstraction processes previously observed for similar systems [5] afforded product ions $(m / z 647$ and 491$)$ that overlap with those due to the main fragmentation process $(m / z 648$ and 492). The abundance of the deprotonated species at $m / z 647$ relative to the base peak in the isotope clusters at $m / z 648$ was found to be $25 \%$ by deconvoluting the experimental peaks and finding the best fit to the sum of the abundances for the 10 major isotope components in each cluster. The formation of oxidized species at $m / z 663$ was previously encountered when NBA was used as a matrix in FAB experiments [16]. The doubly charged species at $m / z 324$ were probably formed as previously suggested for similar systems $[6]$. None of the peaks displayed by the $(+)$ spectra of 1 and $\mathbf{2}$ corresponded to the intact molecule (molecular weight 937.63) ionized by proton attachment or by one-electron removal; however, evidence for the existence in the gas phase of the intact complexes 1 (or 2) has been gathered by the presence in the high-mass region of the $(+)$ spectrum of a cluster at $m / z 1731$ whose unimolecular dissociations [mass-analyzed ion kinetic energy (MIKE)] afforded a very abundant product ion at $m / z 793$ by release of a neutral moiety isobaric with 1 (or 2) (Figure 1). This approach, however, can be only used for relatively low molecular weight compounds.

Tandem mass spectrometry (MS/MS) measurements can be also fruitful in the characterization of the structure of the most significant ionic species present in the spectra (i.e., those formed by release of a single counterion). Previous data on similar systems have shown that the low-energy CID of species of structure $\left[\mathrm{RuL}_{2} \mathrm{~L}^{\prime} \cdot \mathrm{PF}_{6}\right]^{+}$were characterized by the formation

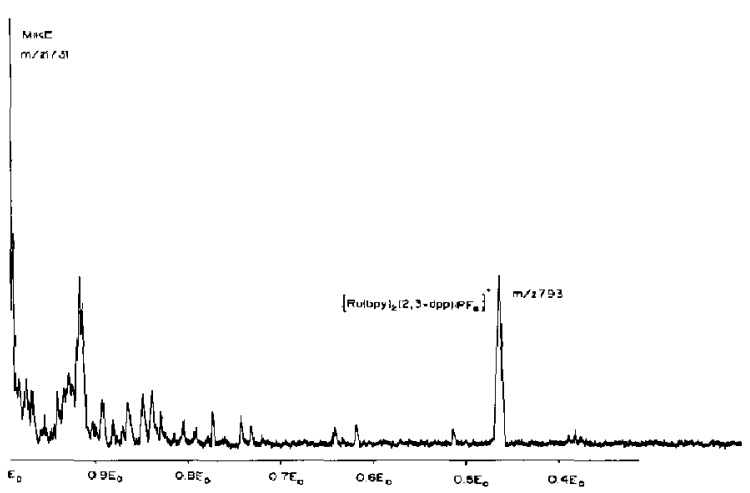

Figure 1. MIKE spectrum of the cluster peak at $m / z 1731$ present in the $(+)$ spectrum of $\left[R 11(b p y)_{2}(2,5-d P p)\right]\left(P F_{6}\right)_{2}$. 


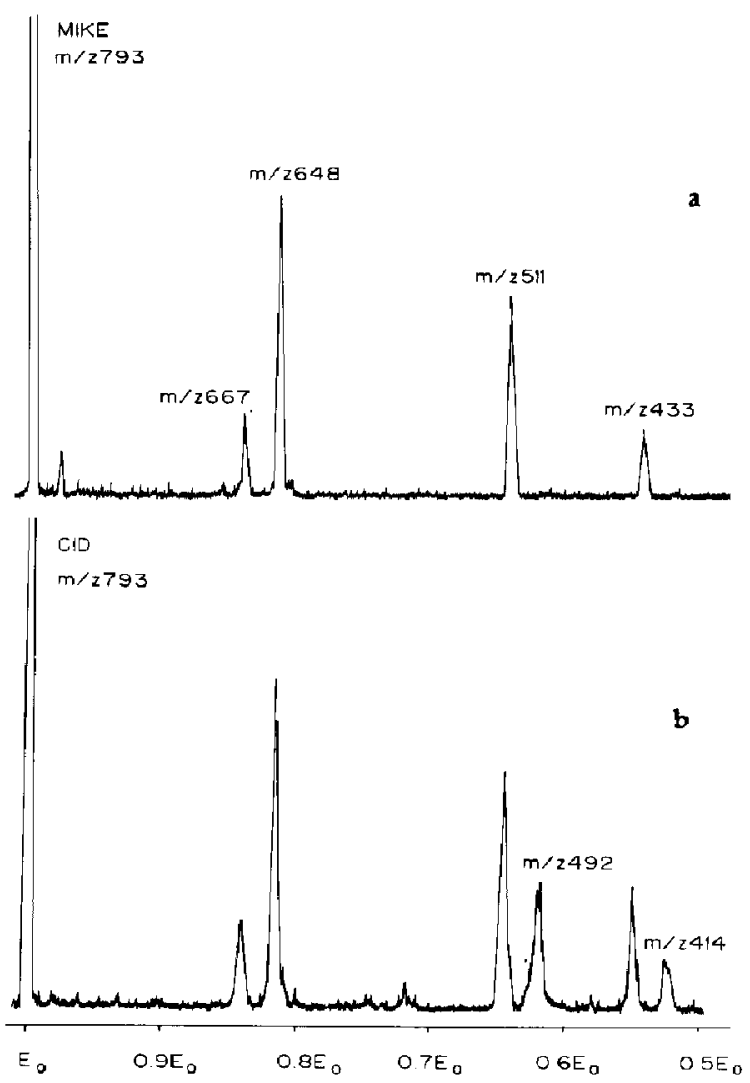

Figure 2. MIKE (a) and CID (b) spectra of [Ru(bpy) $2(2,5-d p p)$. $\left.\mathrm{PF}_{6,}\right]^{+}$produced from compound 1

of a single product ion derived from the concomitant release of one ligand and of a $\mathrm{PF}_{5}$ moiety [5]. On the contrary, the MIKE and high-energy CID spectra of $\left[\mathrm{Ru}(\mathrm{bpy})_{2}(2,5-\mathrm{dpp}) \cdot \mathrm{PF}_{6}\right]^{+}$at $m / z 793$ (Figure 2) produced from 1 displayed competitive and consecutive reactions whereby all the breakdown processes can be clearly identified.

In particular, the MIKE spectrum (see Figure 2a) exhibit the competitive elimination of $\mathrm{PF}_{5}$ and $\mathrm{PF}_{6}$ units, affording the species at $m / z \quad 667$ and 648 , respectively. The latter may well be a composite poak due to the contribution of $m / z 648$ and 647 fragments whose presence was verified in the spectra of the primary ions (see below) but which cannot be resolved with the instrumentation used. The release of the $\mathrm{PF}_{5}$ moiety was then followed by the competitive elimination of one of the two different ligands, affording the product ions at $m / z 511$ and 433 . The formation of $\left[\mathrm{M}-\mathrm{PF}_{5}\right]^{+}$ions at $m / z 667$ requires a rearrangement whereby the original counterion $\mathrm{PF}_{6}$ is substituted in the coordination sphere by a fluoride species. The CID spectra (Figure 2b) were characterized by the consecutive processes leading from $m / z 511$ and 433 to species at $m / z 492(491)$ and $414(413)$, respectively, due to elimination of $\mathrm{F}$ (or HF) moieties. The same behavior was shown by the isobaric complex 2 . In the case of $\mathbf{1}$ and 2 , therefore, even in the absence of a molecular ion species, the FAB (+) spectra and the use of MS/MS techniques provide a means for the characterization of the analytes.

The ruthenium complex 3 differs from 1 by the presence of a cationized nitrogen atom on one the pyrydil moieties of the dpp ligand; therefore the inner cation bears three positive charges balanced by an equivalent number of counterions. The highest observable molecular cluster in the $(+)$ ionization mode still corresponds to the $\left[\mathrm{M}-\mathrm{PF}_{6}\right]^{+}$species at $m / z$ 953, whereas two different types of doubly charged species are present at $m / z 404$ and 331.5 of composition [M $\left.2 \mathrm{PF}_{6}\right]^{2+}$ and $\left[\mathrm{M}-3 \mathrm{PF}_{6}\right]^{2+}$, respectively (Figure 3 ). The formation of the latter shows that the sputtering of triply charged species, even when chemically possible as in the case of compound 3, is not favored by FAB, under our experimental conditions. It appears therefore that the occurrence of doubly charged cations of different composition is a function of the number of counterions present in a given complex, as the spectra of compounds 1 (or 2) and 3 demonstrate. This behavior, although helpful in the evaluation of the composition of a compound of more or less known structure, makes the interpretation of spectra of unknown compounds intriguing.

The formation of the monocharged cations corresponding to the release of two and three $\mathrm{PF}_{6}^{-}$units at $m / z 808$ and 663, respectively, was accompanied by proton abstraction and oxidation processes, as observed for compounds 1 and 2, and probably by the release of the methyl moiety from the ligand, as shown by the appearance of satellite peaks on both sites of the main cluster due to the elimination of the counterions (Figure 3). The MIKE spectrum of the $\left[\mathrm{M}-\mathrm{PF}_{6}\right]^{+}$ species at $m / z 953$ displayed abundant elimination of a $\mathrm{PF}_{6}$ unit $(\mathrm{m} / \mathrm{z} 808,66.1 \%)$ followed by the consecutive displacement of the remaining counterion, giving

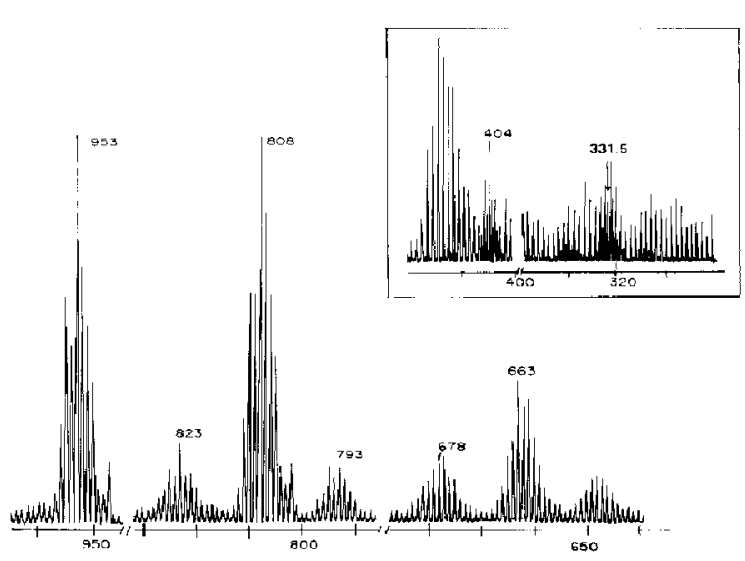

Figure 3. Positive $\mathrm{FAB}$ spectrum of [Ru(bpy) $\left.)_{2}(2,3-\mathrm{dpp}-\mathrm{Me})\right]$ $\left(\mathrm{PF}_{6}\right]_{3}$. 
rise to product ions at $m / z 663(5.3 \%)$, whereas information on the structure of the cation can be gathered only by the presence of a minor peak at $\mathrm{m} / \mathrm{z} 545$ (2.6\%), which could be due to the consecutive elimination of $\mathrm{PF}_{5}$ and one bipyridine moiety. The other product ions at $m / z 827(5.3 \%), 701(13.2 \%)$, and 682 (7.4\%) correspond to competitive or consecutive elimination of $\mathrm{PF}_{5}$ or $\mathrm{PF}_{6}$ units. The $\mathrm{CID}$ spectrum did not provide further information. The striking difference observed in the tandem mass spectra of compounds 1 (or 2) and 3 has to be ascribed therefore not to structure of the cation, 1 and 3 being very similar, but to the presence of an extra anion in one of the examined reacting species. Therefore, the spontaneous (MIKE) and collision-activated unimolecular dissociations of the monocharged species examined above gives relevant information on the structure of the cation only when a single counterion is present in its coordination sphere. The positive FAB spectrum of the polynuclear ruthenium complex 4 displayed the species $\left[\mathrm{M}-\mathrm{PF}_{6}\right]^{+}$ as the highest mass observable cluster and singly and doubly charged cations of both $\left[\mathrm{M}-2 \mathrm{PF}_{6}\right]$ and $[\mathrm{M}-$ $\left.3 \mathrm{PF}_{h}\right]$ composition. The latter did not provide direct proof of the composition of the cationic moiety of 4 , whereas the structural features of the spectrum provide further insight into the energetics of the sputtering of species bearing more than two positive charges. The breakdown pattern of this multinuclear complex shows the presence at lower masses of [Ru(bpy $)_{2}(2,5-$ dpp) $\left.\cdot \mathrm{PF}_{6}\right]^{+}$species at $m / z$ 793. The latter is also obtained under the same experimental conditions from complex 1 (see below). Its formation in the case of 4 could be due either to the gas-phase process or to radiation damage. The MIKE spectrum of the [Ru(bpy) $\left.{ }_{2}(\mu-2,3-\mathrm{dpp})\right]_{2} \mathrm{RuCl}_{2} \cdot \mathrm{PF}_{6}^{+}$at $m / z \quad 1903 \mathrm{did}$ not show any unimolecular dissociation leading to $m / z$ 793; however, as discussed above in the case of the unimolecular dissociation of 3 , a given precursor containing more than one $\mathrm{PF}_{6}$ unit preferentially releases the counterion moieties, thus providing less information on the structure of the core of the complex. Nevertheless, it can be assumed that the species at $m / z 793$ is not formed by solvolysis of 4 , caused by the matrix, previous to the sputtering event because its breakdown pattern (Figure 4b) differs significantly in the relative intensities of the fragments from that observed in the $(+)$ spectrum of complex 1 (Figure $4 a$ ).

The data discussed above point out that the ruthenium complexes examined here can be characterized by positive $F \wedge B$; however, only indirect evidence is provided in some cases on the composition of the intact molecule. The use of doubly charged species to infer the composition of the cationic moicty [6] is limited to only very simple systems. The occurrence in fact of doubly charged species with different composition in the spectra of 3 and 4 suggests that structural assignment of the inner cation would be less straightforward in the case of polynuclear ruthenium complexes.
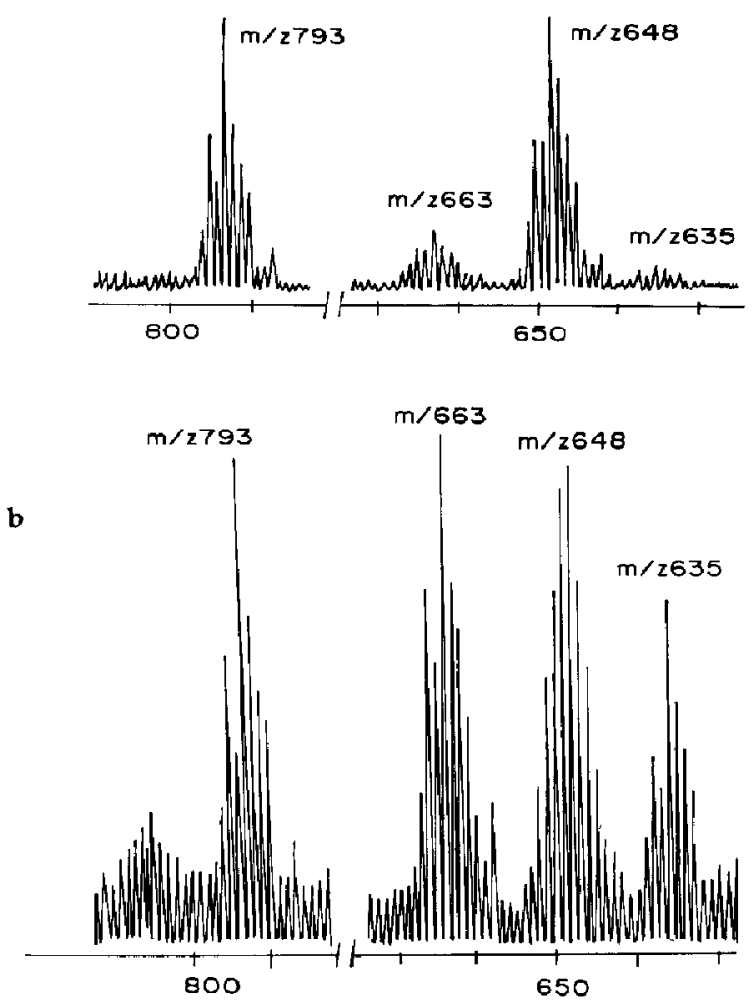

Figure 4. (a) Positive FAB spectrum of [Ru(bpy) $\left.)_{2}(2,5-\mathrm{dpp})\right]$ $\left(\mathrm{PF}_{6}\right)_{2}$, high-mass region; (b) positive $\mathrm{FAB}$ spectrum of $\mathbf{R} \mathbf{R}$ (bpy) $\left.)_{2}(\mu-2,3-d p p)\right]_{2} \operatorname{RuCl}_{2}\left(\mathrm{PF}_{6}\right)_{4}$, low-mass region.

The physicochemical properties of the molecules examined point out that they could undergo electron capture in the presence of free electrons such as those produced during the FAB event. The negative ion (-) spectrum of the isomeric compounds 1 and 2 displayed in the high-mass region two abundant clusters at $m / z 938$ and 1083. The former corresponds to the intact salt ionized by one-electron capture, whereas the latter is formed by the association of an extra $\mathrm{PF}_{5}^{-}$ counterion-no significant peaks due to fragmentation processes were present in the spectrum. The isotope distribution within the two clusters corresponds to what one would expect from the molecular composition of the analyte; therefore we can conclude that the spccies at $m / 2938$ contains no $[\mathrm{M}-\mathrm{H}]^{-}$ions. According to the known electrochemical and photochemical behavior of these species in solution [3], the first reduction $\left(E_{1 / 2}--1.03 \mathrm{~V}\right.$ for 1 and $-1.06 \mathrm{~V}$ for 2 ) is centered on the dpp ligand because its $\pi^{*}$ orbital is the lowest lying LUMO. The lack of fragmentation observed in the spectra is easily accounted for by the exceptionally high stability of the radical anions in the gas phase, which parallels the observation that species containing even doubly reduced dpp ligands are still 
stable in coordinating solvents (namely, acetonitrile). The MIKE spectrum of the radical anion of compound 2 at $m / z 938$ (Figure 5) displayed the elimination of a $\mathrm{PF}_{5}$ neutral moiety, giving rise to a negatively charged species in which, presumably, one $\mathrm{F}^{-}$is transferred to a coordination site left open by a chelating ligand (probably dpp) now behaving as a monodentate one. This process should correspond to a rearrangement reaction with high enthropy requirements because it is not observed in the spectrum of the stable ions. The same behavior was exhibited by the ruthenium complex 1, which has the same elemental composition of 2 and differs only in the structure of one of the ligands.

The (-) FAB spectrum of species 3 displayed peaks at $m / z 1243,1098$, and 953 corresponding to $[\mathrm{M}+$ $\left.\mathrm{PF}_{6}\right]^{-}, \mathrm{M}^{-}{ }^{-}$, and $\left[\mathrm{M}-\mathrm{PF}_{6}^{-}\right]$, respectively. The molecular composition of the analyte can be easily assigned from the first two ion clusters, whereas the elimination of a $\mathrm{PF}_{6}$ radical from the molecular ion can be related to the structure of the complex, which has a positively charged dpp so that its first and second reduction potentials become much lower, more or less the same of those of a species that contains a $\mu$-dpp ligand that bridges two metal centers (see below). The MIKE spectrum of the molecular ion of 3 at $m / z 1098$ displayed the elimination of a $\mathrm{PF}_{5}$ neutral moiety, presumably via a reaction mechanism similar to that in operation with species 1 and 2. A remarkable example is provided by the reactivity of the dinuclear Ru(II) complex 4 under particle bombardment. Abundant species at $\mathrm{m} / \mathrm{z} 2048$ were in fact observed, corresponding to the intact molecule that has captured a low-encrgy electron (Figure 6a); FAB mass spectrometry is probably the only reliable analytical method that can provide straightforward information on the composition of species such as those considered here. The other ionic species detected in the spectrum of 4 correspond to the

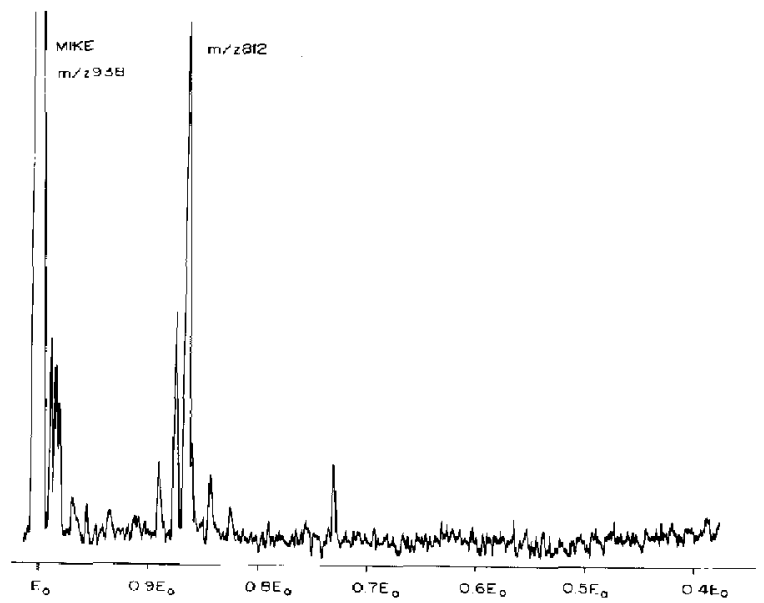

Figure 5. MIKE spectrum of the radical anion of $\left[\operatorname{Ru}(b p y)_{2}(2,3-\right.$ $\mathrm{dpp})]\left(\mathrm{PF}_{6}\right)_{2}$
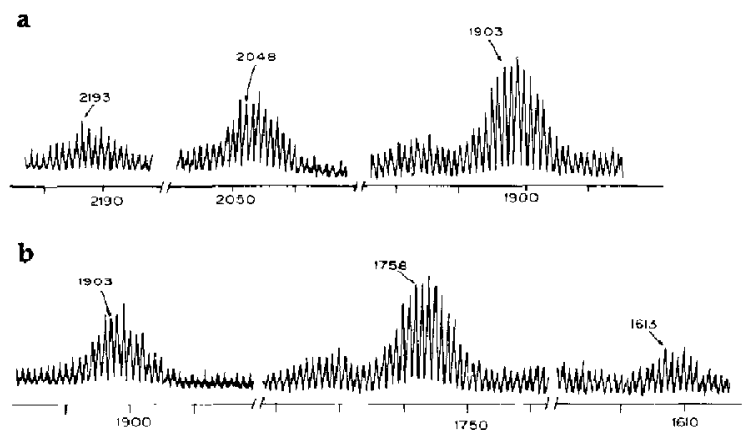

Figure 6. FAB spectra of $\left[\mathrm{Ru}(\mathrm{bpy})_{2}(\mu-2,3-\mathrm{dpp})\right]_{2} \mathrm{RuCl}_{2}\left(\mathrm{PF}_{6}\right)_{4}$, high-mass region; (a) ncgative ions; (b) positive ions.

formation of the $\left[\mathrm{M}+\mathrm{PF}_{6}\right]^{-}$adduct at $m / z 2193$ and to the consecutive release of $\mathrm{PF}_{6}$ radical units giving rise to species at $m / z 1903$ and 1758 .

This reactivity can be correlated to the presence of two $\mu$-dpp ligands that in solution undergo [3] two consecutive low-potential one-electron reduction processes $\left[E_{1 / 2}\right.$ approximately -0.5 and $-0.7 \mathrm{~V}$ ) affecting the two different dpp moieties.

From an analytical point of view, the characterization of multinuclear $\mathrm{Ru}$ complexes of the type discussed above can be confidently carried out by matching the molecular ion regions of both the $(+)$ and (-) FAB spectra (Figure 6). In the case of compound 4 , whose behavior from the data reported here and from those available from the literature and from our laboratory can be considered typical, the identification of the ionized intact salt at $m / z 2048$ in the (-) spectrum (see Figure 6a) is supported by the presence in the $(+)$ spectrum (see Figurc $6 \mathrm{~b}$ ) of the species at $m / z$ 1903. Moreover, with reference to the $(+)$ spectrum, it is also possible to assign without ambiguity a structure to the cluster at $\mathrm{m} / \mathrm{z} 2193$ present in the $(-)$ spectrum. It is in fact reasonable to presume that it corresponds to the adduct $\left[\mathrm{M}+\mathrm{PF}_{6}\right]^{-}$and does not represent a molecular ion.

\section{Conclusions}

The combined use of $(+)$ and $(-)$ FAB spectra enables a full characterization of the ru(II) compounds discussed above. A key role is played by the formation of radical anions from the intact salts by a redox process driven by the low values of the reduction potentials of dpp and byp $\mathrm{Ru}$ (II) complexes. MS/MS investigations can be of valuable interest only for very simple cationic species. Both MIKE and CID measurements performed on species 3 and 4 , either in the $(+)$ or $(-)$ ionization mode, in fact did not give relevant information as to the structure of the core of the complex. When the structure of the complex is characterized by the presence of a polycharged cation, the only possibility of 
obtaining molecular ion information is to resort to the investigation of negative ions.

\section{Acknowledgments}

A Ministero $40 \%$ grant is gratefully acknowledged. Thanks are due to Dr. Francesco Greco for collecting the spectra and to Professor Antonio Ranieri for performing the calculations on the overlapping clusters.

\section{References}

1 Balzani, V.; Scandola, F. Supramolecular Photochernistry; Horwood: Chichester, 1990.

2. Chow, C. S.; Barton, J. K. J. Am. Chem. Soc. 1990, 112, 2839.

3. Denti, G.; Campagna, S.; Sabatino, L.; Serroni, S.; Ciano, M.; Balzani, V. Inorg. Chem. 1990, 29, 4750, and references therein.

4. Cerny, R. L.; Sullivan, B. P.; Bursey, M. M.; Meyer, T. J. Inorg. Chem. 1985, 24, 397 .
5. Liang, X.; Suwanrumpha, S; Freas, R. B. Inorg. Chem. 1991, 30,652 .

6. Miller, J. M.; Dalasanmugam, K.; Nye, J.; Deacon, G. B.; Thomas, N. C. Inorg. Chem. 1987, 30, 652.

7. Williams, D. H.; Findeis, A. F.; Naylor, S.; Gibson, B. W. J. Am. Chem. Soc. 1987, 109, 1980.

8. Cerny, R. L.; Gross, M. L. Anal. Chem. 1985, 57, 1160.

9. Hand, O. W.; Detter, L. D.; Lammert, S. A.; Cooks, G. R.; Walton, R. A. J. Am. Chem. Soc. 1989, 111, 5577.

10. Sindona, G. In: Mass Spectrometry in the Biological Sciences: A Tutorial; Gross, M. L., Ed.; Kluwer: Dordrecht, 1992; pp $383-405$.

11. Laramée, J. A.; Arbogast, B.; Deinzer, M. L. Amal. Chem. 1989, 61,2154

12. Miller, J. M. Mass Spectrom Rev. 1989, 9, 319-347.

13. Kyranos, J. N.; Vouros, P. Biomed. Environ. Mass Spectrom $1990,30,652$.

14. Clayton, E.; Wakefield, A. J. C. J. Chem. Soc, Chem. Commun. $1984,969$.

15. Campagna, S.; Denti, G.; Serroni, S.; Ciano, M.; Balzani, V. Inorg. Chem. 1991, 30, 3728.

16. Zerilli, L. F.; Vekey, K. Org. Mass Spectrom. 1991, 26, 939. 